\title{
USO E DESUSO DA TECNOLOGIA: UM DIAGNÓSTICO
} USO Y DESUSO DE LA TECNOLOGÍA: UN DIAGNOSTICO

\author{
José Eduardo Rocha Silva ${ }^{\mathrm{i}}$ \\ Mestrando do Programa de Pós-Graduação em Ensino (PPGEn) \\ Universidade Estadual do Sudoeste da Bahia - Campus de Vitória da Conquista \\ contato@joseeduardo.com.br
}

Maria Deusa Ferreira da Silva ${ }^{\text {ii }}$

Professora Titular da Universidade Estadual do Sudoeste da Bahia;

Coordenadora do Programa de Pesquisa em Educação Matemática

mariadeusa@gmail.com

\section{Resumo}

Este artigo discute o uso das ferramentas tecnológicas pertencentes ao professor e a escola e que são disponibilizados tanto para os professores quanto para os alunos do ensino médio, no âmbito dos laboratórios de informática da rede pública estadual de ensino. Como suporte ao entendimento deste cenário, traçamos um breve estudo sobre a transformação social e histórica da tecnologia, buscando entender a relação entre a necessidade do uso e a cultura do não uso das tecnologias disponibilizadas em outros espaços dentro e fora da escola. Dentro da abordagem qualitativa, este estudo configurase, também, como uma pesquisa de campo. Os dados foram coletados mediante um questionário fechado, construído na versão impressa e web, contendo questões de múltiplas alternativas, organizada em sete categorias, aplicado e enviado a 50 professores da rede estadual de ensino do município de Vitória da Conquista, BA, dos quais 36 retornaram. Para este artigo, trazemos a análise de duas categorias: uso de equipamentos/meios tecnológicos próprios e uso de equipamentos tecnológicos da escola. Os resultados da pesquisa apontam que os professores estão utilizando de equipamentos/meios próprios como suporte para a suas aulas, entretanto, pouco interesse por parte destes em usar os espaços e equipamentos da escola, não sendo a predisposição dos poucos interessados suficiente para contemplar a demanda ociosa de alunos dispostos a utilizarem os equipamentos em tais 
espaços; a existência de um cenário escolar repleto de equipamentos velhos e novos em desuso, sendo desgastados pelo tempo em inatividade.

Palavras-chave: Tecnologia digital. Novas tecnologias. Mediação. Laboratório. Uso e desuso das tecnologias.

\section{Resumen}

En este artículo se discute el uso de herramientas tecnológicas pertenecientes al maestro y la escuela y están disponibles tanto para los profesores y para los estudiantes de la escuela secundaria, en los laboratorios de computación del sistema de escuelas públicas del estado. Para apoyar la comprensión de este escenario, se dibuja un breve estudio de la transformación social e histórico de la tecnología, tratando de comprender la relación entre la necesidad de usar y cultura de la no utilización de las tecnologías disponibles en otros espacios dentro y fuera de la escuela. En el enfoque cualitativo, este estudio se configura también como una investigación de campo. Los datos fueron recolectados a través de un cuestionario cerrado, construido en forma impresa y web, que contiene temas múltiples alternativas, organizada en siete categorías, aplican y se envían a 50 maestros del estado de la ciudad de Vitória da Conquista de la educación, BA, de los cuales 36 regresaron. Para este artículo, traemos el análisis de dos categorías: uso de equipos propios medios / tecnológicas y la utilización de equipos de tecnología de la escuela. Los resultados de la encuesta muestran que los profesores están utilizando equipos propios medios / as de apoyo para sus clases, sin embargo, poco interés de su parte para utilizar los espacios e instalaciones escolares, al no ser la predisposición de los pocos interesados lo suficiente como para tener en cuenta la demanda estudiantes ociosos dispuestos a utilizar el equipo en dichos espacios; la existencia de un entorno escolar completo de equipo viejo y nuevo en desuso, siendo usado por la inactividad tiempo.

Palabras clave: Tecnología digital. Nuevas tecnologías. Mediación. Laboratorio. Tecnologías de uso y desuso.

\section{Introdução}

A modernidade está imersa num mundo tecnológico de rápidas e constantes mudanças. A formação do cidadão se insere neste contexto tecnológico como fator complementar de uma educação inclusiva e atual, mormente, quando se tentam fazer comparações entre o que se lançou ontem e o que vai ser lançado amanhã. $O$ viés da comparação traz uma grande questão: as novas ferramentas tecnológicas desenvolvidas para a educação serão suportadas pelos 
equipamentos tecnológicos presentes e não tão recentes nas escolas? Em alguns casos, um upgrade resolve o problema momentâneo, entretanto, fazer esse upgrade de equipamentos ou software se esbarram no campo da falta de conhecimento da sua utilização e, consequentemente, da conscientização de que o uso de outro espaço que não seja a sala de aula, também é um quesito indispensável ao processo mediador da aprendizagem em grupo ou individualmente.

Não é de agora o problema da aprendizagem dentro e fora da sala de aula. Remontando a história, vê-se que a questão é histórica e atravessa gerações desde os tempos de ensino à distância por correspondência, datado de 1728, passando pela máquina de escrever, até chegar aos computadores. Tamanho foi o desenvolvimento da tecnologia para o serviço de telefonia, que os seus recursos viabilizaram a comunicação, contemplando tanto o ensino à distância quanto o presencial. A educação passu a se inserir neste contexto, ampliando as suas necessidades e contemplando-as com a criação de salas de aulas com TD e escolas equipadas com laboratório de informática.

Todo desenvolvimento histórico da tecnologia contribuiu para o advento da nova modelagem do ensino e aprendizagem. No sentido do desenvolvimento para a viabilização da comunicação com a mínima barreira em distâncias, surgiram os rádios comunicadores portáteis, também denominados transceptores de mão, sem fios. Como exemplo, tomamos o walkie-talkie $^{i i i}$ modelo SRC536 que pesava 15,9kg em 1943 pela japonesa Motorola, e ao desenvolvimento do computador utilizando válvula de rádio em 1946. O mundo se percebeu tecnológico e descobriu a maravilha do entretenimento no ano seguinte, com a introdução dos televisores de tubo nos lares de todo o mundo em 1947. Tal a impressão provocada pela tv, o mundo também se maravilhou neste mesmo ano, com o uso restrito da comunicação por telefonia sem fios, em uso exclusivo, inicialmente, pelos seus engenheiros inventores. Ressalta-se, entretanto, que a tecnologia utilizada era estritamente precária, se comparada à de hoje, entretanto, para a época era muito surpreendente.

Outro surpreendente surgimento foi o modelo Russo em 1955 (ROSSII), protótipo de curto alcance e peso de médio de $1,2 \mathrm{~kg}$, desenvolvido pelo russo Leonid Kupriyanovich (MOZGA, 2013) com registro de patente em 1957.

Em 1973, a rede de telefonia desfrutou pela primeira vez da primeira chamada de um telefone móvel para um fixo. Em 10 anos de intenso uso e pesquisa, a empresa Motorola, no ano de 1983, lançou o modelo DynaTAC 800x, com peso médio de $0,79 \mathrm{~kg}$, tamanho 
aproximado de $33 \mathrm{~cm}$ de altura, e pronto para ser adaptado em carro, marcando a primeira geração do celular na década seguinte. Portanto, em 1993, uma operadora da Finlândia mandou a primeira mensagem via telefone móvel para móvel, dando início aos primeiros ensaios sobre o uso desses equipamentos e, consequentemente, o desuso rápido, provocado pela corrida do modismo tecnológico (JOSÉ, 2007).

Essa corrida histórica pela melhor ferramenta e equipamentos TD, reforça a ideia de que a tecnologia e a ciência se vinculam para traçar novas diretrizes no universo das descobertas, transcendendo sua inovação dia a dia. Neste contexto, este trabalho tem por objetivo fazer um levantamento dos equipamentos tecnológicos próprios e da escola que são usados pelo professor do ensino médio, como suporte as suas aulas. Este objetivo é parte de nossa pesquisa de mestrado em desenvolvimento.

\section{Alinhando a Tecnologia e a Sala de Aula}

A interconexão de todas as áreas da ciência e educação na rede mundial de computadores imprime ao mundo uma dinâmica na atualização da informação e do conhecimento. Desta atual realidade, tornar-se usuário e interconectar-se com as ferramentas da TD, é o mesmo que está com o mundo da informação na palma da mão. Por outro lado, não se imergir neste universo on-line, é tornar-se fora da dinâmica da aprendizagem que estas ferramentas proporcionam. Contudo, identificar a solução ideal de ensino e aprendizagem com uso das TD na sala de aula, ainda é uma preocupação mundial e um grande desafio para os educadores. Sobre este ponto Freire $(1984$, p.1) não poderia ter sido tão claro ao afirmar: "Faço questão enorme de ser um homem de meu tempo e não um homem exilado dele".

Está no tempo e não exilado dele, saber manipular as ferramentas e aplicá-las convenientemente numa sala de aula, não é algo que surge do nada como um toque de mágica, sendo necessária uma anterioridade de conhecimento dos processos, dando novas formas e utilidades para as TD, levando-nos a pensar sobre a questão da utilidade, do uso, e as decorrências do não uso ou desuso, no aspecto da construção e da aceleração da aprendizagem, para uma melhor qualidade do ensino da educação básica.

Ao uso do novo que segue ao desuso do "antigo" em TD, Borba, Scucuglia e Gadanidis (2014) fazem uma analogia deste encontro como uma dependência mútua e necessária, sempre abertos para um "mais novo", sendo importante destacarmos que o 
surgimento de cada fase de uso não exclui ou substitui a anterior. Há certa "sobreposição" entre as fases, elas vão se integrando (BORBA; SCUCUGLIA; GADANIDIS, 2014). A integração é tão relevante que muitas das tecnologias "antigas" ainda são utilizadas, deixando sempre diversas perguntas em aberto, seguindo um ciclo de fases e construções inovadoras.

Como uma enxertia, o novo traz as raízes do "velho", e o domínio da informação se completa e se confirma, tal o pensamento dos autores em sintonia com o pensamento freireano de que "a tecnologia não surge da superposição do novo sobre o velho, mas o novo nasce do velho" (ALENCAR, 2005). Da nova perspectiva da introdução do novo na educação, surgem novos cenários qualitativos para dinamizar as aulas, professores e alunos se debruçam nas cadeiras para adentrar-se na nova fase e perceberem-se imersos no mundo da educação e das TD como mediadora da aprendizagem. Ainda, os autores Borba, Scucuglia e Gadanidis (2014) afirmam que esse cenário da aprendizagem nos leva a perceber o modo como atuamos em sala de aula ou desenvolvemos pesquisas, de modo que, em grande parte estão orientados por noções tecnológicas mediadoras e que as próprias tecnologias não são figurantes nos cenários cognitivos. Humanos e tecnologias são protagonistas do processo cognitivo.

Sweller (2003) tem nos ajudado a compreender este protagonismo da interação humana com a tecnologia alinhada ao processo cognitivo, teorizando essa relação como "um conjunto universal de princípios que resultam em um ambiente de aprendizagem eficiente e que consequentemente, promovem um aumento na capacidade do processo de cognição humana" (SWELLER, 2003, apud SANTOS e TAROUCO, 2007, p. 3).

Desse modo, os dispositivos tecnológicos mediam o desenvolvimento cognitivo e disponibilizam informações que alteram o modo de pensar e de agir, ao mesmo tempo em que estimulam o entretenimento e dinamizam as ações práticas do ensino e da aprendizagem.

Kenski observa nessa dinamização das ações uma transformação radical na organização social com amplo reflexo na comunicação, cultura e aprendizagem, em que ampliam a utilização das capacidades humanas (muito além da cognição) em processos diferenciados pela busca de conhecimento.

Os atributos das novas tecnologias digitais tornam possíveis o uso das capacidades humanas em processos diferenciados de aprendizagem. A interação proporcionada por softwares especiais e pela Internet, por exemplo, permite a articulação das redes pessoais de conhecimentos com objetos técnicos, instituições, pessoas e múltiplas realidades... para a 
construção de espaços de inteligência pessoal e coletiva (KENSKI, 2003, p. 5)

\section{A formação do professor e os espaços de ensino e aprendizagem digitais}

Reconhecidos como um dos países mais tecnológicos do mundo, Japão, Estados Unidos e Suécia têm suas bases educacionais assentadas na inclusão digital e no uso constante de ferramentas tecnológicas na escola como reforço mediador da aprendizagem. Decerto, que o cenário da educação tecnológica brasileira seja bem diferente dos países desenvolvidos, entretanto, por maiores que sejam as diferenças, todos se igualam numa lacuna em comum: descobrir a melhor ferramenta tecnológica e o uso eficaz técnico-metodológico para a dinamização do ensino e a eficiência da prática no processo de aceleração da aprendizagem.

O mundo todo está se movendo em pesquisas para dinamizar o processo educacional da escola, em encontrar a melhor ferramenta metodológica que modernize o ensino e a aprendizagem dos alunos nas salas de aulas, nos laboratórios e outros espaços do saber.

Inovações e mudanças imprimem necessidades e "não há dúvida de que a escola precisa mudar, de que é preciso que nasça uma nova concepção de construção do conhecimento, uma nova forma de conceber a escola" (SILVA, 1999, p.33).

Silva fala desse momento como necessário e oportuno para que o professor se forme e se insira neste contexto tecnológico do ensinar.

\footnotetext{
Assim, a partir do momento em que os novos instrumentos tecnológicos começaram a entrar na escola, as preocupações voltaram-se para a necessidade de formar o professor para utilizá-los. Por exemplo, em países como Estados Unidos, França e Inglaterra, dos anos oitenta em diante, houve uma grande proliferação de computadores nas escolas de ensinos fundamental e médio, aliada a uma grande produção de softwares educacionais. Isso provocou um intenso debate em torno da formação continuada de professores, uma vez que tornou-se de consenso geral que o sucesso na informatização dessas escolas dependia de professores aptos a implementá-la (1999, p.35).
}

Corroboramos com Silva (1999) quando nos diz que, enquanto não se formar o professor para o uso das TD seja na sala de aula ou nos espaços de laboratório de informática, quando inovados, teremos o desuso de equipamentos novos como um fato lamentável. O fato de não utilizar os equipamentos disponíveis, sugere o não cumprimento das propostas pedagógicas, disponibilizada para os professores e alunos da escola. Uma relação de 
construção do uso coletivo da tecnologia deverá ser priorizada, razão pela qual, essa construção do saber coletivo e colaborativo é uma das exigências do mundo moderno.

As potencialidades das inovações tecnológicas já permitem prevê que os ambientes de ensino e de aprendizagem num futuro não muito distante serão bastante diferentes daqueles que conhecemos hoje. [...] que vai muito além dos épsilons e deltas costumeiros das aulas presenciais tradicionais (BORBA, CHIARI, 2013, p.169).

Com o advento da revolução das TD e por consequência a utilização das TIC, com destaque para os celulares e smartphones, por exemplo, professores passaram a ter uma preocupação a mais: dispersão dos alunos nas redes sociais em sala, no momento da aula. Esta preocupação traz uma percepção de que algo precisa mudar, não só a maneira como o aluno "entra" na sala, mas como o professor "entra" na tecnologia para fazer dessa, uma ferramenta mediadora do ensino. Moran (2004) sobre esta questão, afirma que os alunos já não suportam essa velha forma de dar aulas, de ficar ouvindo um professor falar por horas, retratando uma verdadeira distância entre o conteúdo das aulas e o da vida.

A aula deve-se dinamizar e movimentar-se, tal qual a dinâmica do movimento da vida. Do movimento tímido, das insatisfações e tédios das aulas convencionais, um novo cenário surge, sinalizando mudanças nos processos pedagógico e metodológico de aprendizagem. As mudanças sinalizadas, segundo (KENSKI, 2008) estão diretamente relacionadas ao empenho do professor como orientador do processo, estimulando o grupo, criando clima e envolvendoos para que minimize as inibições de alguns e melhore a comunicação virtual entre os seus colegas. A autora aponta que o trabalho com a disciplina na web pode ser visto também como atividades informativas e cooperativas, com o fim útil de cumprir um determinado projeto ou tarefas impostas. Talvez, esta dificuldade na condução do ensino via web, por exemplo, seja uma resistência pelo não saber manipular as ferramentas disponíveis em seus espaços, pela falta de treinamento adequado, falta de planejamento ou simplesmente, pela cultura do não uso, porque "não precisa". Moran (2004) preconiza que sala de aula equipada, com atividades diferentes e integrada com a ida ao laboratório de informática para desenvolver atividades de pesquisa, é um potencial recurso para ampliação da aprendizagem, uma vez que a percepção real dos acontecimentos percebidos na web faz com que o enfrentamento das tarefas se completem e se efetive nesses espaços do saber. Se nesses espaços, os equipamentos forem utilizados e os conteúdos pedagógicos acontecerem com professores motivados e bem 
preparados, a aprendizagem em grupos se tornará colaborativa. "O ensino colaborativo prevê, assim, a interdependência do grupo e preocupa-se mais do que o domínio de conteúdos, em melhorar a competência dos alunos para trabalharem em equipes” (KENSKI, 2003, p.9).

Não demarcar a ida ao laboratório de informática, indispondo-se a usar os equipamentos, fará com que tal prática provoque um desuso prematuro - o novo sem uso ficará um "antigo" novo, fomentado pelo descompromisso e inobservância do que está acontecendo no mundo das TD, com perdas irreparáveis ao grupo de alunos que poderiam desenvolver as tarefas e pesquisas virtuais interativamente, colhendo com a prática do não uso, um distanciamento das reações interativas, com consequente mudança de comportamentos e vínculos grupais menos afetivos. A este respeito de interação, afetividade e aprendizagem, Gusmão (2009, p.69) afirma peremptoriamente, que o papel desta característica emocional é "um componente poderoso que influencia o comportamento", ao mesmo tempo em que a dimensão emocional precisa ser encarada como necessária ao desenvolvimento cognitivo do indivíduo. O entrelaçamento em grupos de pesquisas virtuais na web, neste caso específico, em laboratório, poderá contribuir para resgatar o viés facilitador da inovação pedagógica positiva, mediada pelo professor, pela tecnologia e como referência, a realidade do mundo.

Nesta perspectiva, Edméa (2006) aponta que a internet permite a convivência entre os diversos saberes, elimina o antagonismo e promove o entrelaçamento entre a aprendizagem forma/informal, já que as possibilidades de desenvolvimento cognitivo são intensificadas e ampliadas pelas novas formas de sociabilidade existentes na rede, se dinamizando pela prática constante nesses espaços.

Assim como as tecnologias são modificadas em tempos curtos, esses espaços também devem ser reconstruídos constantemente, ampliando as possibilidades de novas descobertas, com sincronismo perfeito entre o antigo e o novo.

Perrenould (1999) desenvolve uma linha de pensamento construtivista no processo do ensino e aprendizagem em que o aluno é o sujeito que constrói seu conhecimento, por meio de experimentações realizadas no computador. Esse construir no ambiente escolar utilizando adequadamente as ferramentas digitais e a interconectividade como recurso, contribui colaborativamente, no processo de formação do professor e do aluno.

Alguns organismos têm se empenhado no contexto colaborativo para promover a mudança com disponibilidade de informações para este fim na web, a exemplo, temos a 
UNESCO, que incentiva e coopera com o programa do governo brasileiro, estimulando a interconectividade e fomentando o acesso a conteúdos educativos definidos em Lei:

A Lei Geral de Acesso à Informação do Brasil, sancionada em 18 de novembro de 2011 e em vigor desde 16 de maio de 2012, foi um grande avanço para o país nesta área. A configuração desse marco legal estabelece regras que demarcam o papel do Estado como fornecedor de informações por ele geradas aos cidadãos e cidadãs, e pela diminuição da exclusão digital.

Com a lei de acesso à informação pública, o Brasil junta-se a mais de 90 países que possuem leis semelhantes, que promovem os dados abertos, livres de licença. Para cumprir a Lei, os órgãos públicos brasileiros são obrigados a disponibilizar seus dados, ou seja, todas as informações públicas devem estar disponíveis nos portais do governo (UNESCO, 2016).

Informação pública, acesso público, utilização de uso comum, laboratório em uso para o acesso, é o que se esperou quando se disponibilizaram esses recursos. Entretanto, a TD no contexto da sala como laboratório ou do laboratório de informática, especificamente, se esbarrou com uma invasão cultural da não utilização, ou rara utilização dos espaços e equipamentos. Tal a realidade dos fatos, que alguns professores perderam o verniz básico e estruturante da educação que indaga, que critica e se inclui digitalmente, conforme preceituou a Lei Geral de Acesso à Informação do Brasil. Freire (1976), solicita que se tenha cuidado para que essa invasão cultural não seja imposta de cima para baixo ou de fora para dentro, para não perder a atitude crítica, indagadora, curiosa e vigilante.

\section{Procedimentos metodológicos da pesquisa}

Ao primar por busca de respostas às perguntas da pesquisa, enunciadas na introdução, este trabalho enveredou-se por uma abordagem qualitativa, teorizada por Chizzotti (2006), que a define como "uma pesquisa sobre a ação quando se trata de estudá-la para compreendêla e explicar seus efeitos". Do ponto de vista dos objetivos, utilizou-se do critério de pesquisa descritiva que, segundo Gil (2002) "objetiva descrever as características de certa população ou fenômeno". Dentro da abordagem qualitativa, este estudo configura-se, também, como uma pesquisa de campo, pois segundo Fiorentini e Lorenzato (2016, p.61) a questão investigativa, "só pode ser efetivamente respondida mediante a realização de um experimento ou da coleta de informações/dados empíricos ou de inserção/intervenção no ambiente estudado".

Revista RBBA $\mid$ Revista Binacional Brasil Argentina 
Em se falando de pesquisa de campo, Trujillo (1982, p.229) apud Marconi e Lakatos (2010, p.169) assevera que "ela não deve ser confundida como a simples coleta de dados", é algo mais que isso, pois exige contar com controles adequados e com objetivos preestabelecidos. Neste sentido, foi estabelecido previamente para esta pesquisa, os objetivos, os métodos e as técnicas de coletas de dados, conforme se relata a seguir.

Os dados foram coletados mediante um questionário fechado, contendo questões de múltiplas alternativas, organizado em sete categorias, assim distribuídas: 1. Dados pessoais, constando do item identificação, sem a obrigatoriedade de identificação pessoal, seguida pela solicitação do sexo; 2. Perfil profissional, objetivando conhecer a área de conhecimento e atuação, o nível de educação escolar, a sua formação acadêmica e o tempo de magistério; 3. Uso de equipamentos/meios tecnológicos próprios, contendo duas questões, solicitando informações sobre o uso de equipamentos próprio utilizados como suporte às aulas; 4. Uso de equipamentos tecnológicos da escola, contendo sete questões, contemplando perguntas sobre o uso do laboratório de informática, lista de equipamentos disponíveis na escola, programa de manutenção e, se os equipamentos atendem às necessidades; 5. Dificuldades do professor em sala de aula, também com sete questões, elencando algumas das principais dificuldades encontradas no desenvolvimento do trabalho nesses espaços; 6. Uso da tecnologia pelo aluno, com três questões remetendo ao tempo de uso de equipamentos na internet, das redes sociais e o uso em sala de aula; 7. Descartes dos equipamentos da tecnologia, inserindo-se neste contexto da categoria, a percepção sobre o descarte dos equipamentos tecnológicos, com cinco questões solicitando informações sobre o destino dos e-lixos e a prática de descartes que evite a contaminação ambiental e a saúde pública.

Este questionário foi construído na versão impressa e web, sendo esta última utilizando a tecnologia do Google Forms v. 2016 e enviada a 50 professores da rede estadual de ensino do município de Vitória da Conquista, BA. Destes 50, 36 retornaram com os questionários respondidos, com 58,3\% do sexo feminino e 41,7\% do sexo Masculino.

Embora o estudo tenha uma abordagem qualitativa, utilizou-se de certo tratamento estatístico para a construção de gráficos, disponível no software Google Forms, visando uma melhor leitura e tratamento dos dados.

Para a análise dos dados revisita-se Bardin (2009), que tece orientações a esse respeito. Assim, com base nessa autora foi feita uma primeira leitura dos dados, chamada "leitura flutuante", cuja função é deixar invadir-se por impressões e orientações, para então 
fazer uma apreciação mais cuidadosa, seguida de um processo de categorização. Neste estudo, as categorias foram preestabelecidas intencionalmente no questionário, haja vista o contato anterior com o livro Análise de Conteúdo, de autoria de Bardin, em que propiciou antecipar a organização das perguntas do questionário em categorias, facilitando a posteriori, a leitura e análises. O critério de categorização foi semântico, uma vez que as categorias são temáticas e propiciam maior rapidez e eficácia na condição de se aplicar a discurso direto e simples (BARDIN, 2009).

\section{Das discussões e análises}

Para este artigo, trazemos a análise das categorias 3 (Uso de equipamentos/meios tecnológicos próprios) e 4 (Uso de equipamentos tecnológicos da escola), conforme descritas anteriormente.

A categoria Uso de equipamentos/meios tecnológicos próprio, apontou que todos os pesquisados utilizam de algum equipamento pessoal para preparar suas aulas, sendo os mais declarados PC/Notebook (91,4\%), impressora (42,9\%), internet (40\%), tablet (25,7\%).

Gráfico 1: equipamentos próprios utilizados pelo professor



Dos resultados, podemos inferir que os professores estão utilizando de equipamentos/meios próprios como suporte para a suas aulas, demonstrando que estes são orientados por noções tecnológicas mediadoras, não sendo as tecnológicas ferramentas figurantes nesse processo, conforme apontam Borba, Scucuglia e Gadanidis (2014). Tais orientações sugerem ser consequência do grau de especialização dos pesquisados, com 76,5\% especialista e $14,7 \%$ mestres. 
Ainda nesta categoria, foi perguntado sobre o tempo de uso semanal de tais equipamentos/meios tecnológicos, verificando que, aproximadamente, $85,7 \%$ dos pesquisados utilizam por mais de 2 horas semanais.

Quanto às perguntas da categoria Uso de equipamentos tecnológicos da escola, os pesquisados responderam que 79,4\% de suas escolas têm laboratórios, 5,9\% não têm e, 5\% não sabem ou não responderam. Quanto ao uso dos equipamentos da escola/laboratórios de informática como suporte às aulas, 5\% disseram que utilizam constantemente, $65 \%$ não utilizam e $30 \%$ raramente utilizam. Perguntado aos pesquisados se os equipamentos dos laboratórios atendem às suas necessidades, obtivemos as seguintes afirmativas: $37,1 \%$ que não atendem às suas necessidades; $31,4 \%$ que estão em estado de desuso e/ou obsoletos; $22,9 \%$ tiveram seus laboratórios desativados. Apenas $8,6 \%$ consideraram que os equipamentos atendem às suas necessidades.

Tais resultados sugerem que a não utilização dos destes espaços, não está relacionada ao interesse do aluno, mas se encontra intimamente ligada ao desinteresse do professor, em conduta na contra mão do projeto originário de implantação destes espaços promovidos pelo Estado e, possivelmente, pelo projeto pedagógico da escola.

Se por um lado, a prevalência de especialistas e mestres na pesquisa não foi um fator determinante da percepção do espaço do laboratório de informática, como um importante lugar de aprendizagem, é consenso, que a sala de aula não é o único espaço do saber. Segundo Moran (2004), as atividades em sala de aula devem ser integradas com as idas ao laboratório, visando potencializar a aprendizagem com uma melhor percepção da realidade dos acontecimentos, mediados pela web.

Esta prevalência na formação de especialistas e mestres, tem se mostrado distante da realidade do mundo tecnológico atual quanto ao uso e ao desuso das tecnologias educacionais. Daí, perguntamos: a formação do professor para o uso da tecnologia só se dará em uma formação específica para a área? Não seriam as especializações na área de ensino também responsáveis por essa formação? Nesse sentido, remetemos a Silva (1999) quando observa que a não utilização dos equipamentos provoca o não cumprimento das propostas pedagógicas, disponibilizada para o professor no ensino.

No que diz respeito à manutenção de equipamentos, foi perguntado se há programas ou projetos de manutenção para os aparatos tecnológicos do laboratório, ao que obtivemos as 
seguintes respostas: $71,4 \%$ disseram que não há manutenção; $20 \%$ desconhecem e, $8,6 \%$ afirmaram existir manutenção, conforme se observa no gráfico a seguir:

Gráfico 2: Existência de programas/projetos de manutenção de equipamentos dos laboratórios

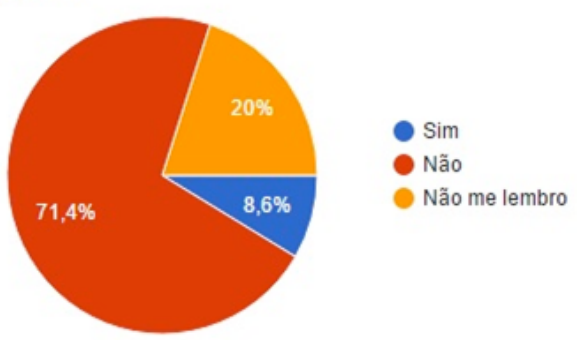

Fonte: acervo pessoal

Ao expressivo número 71,4\% que representa a ausência de programas de manutenção, consideramos uma estreita relação aos índices encontrados sobre o estado de uso dos equipamentos dos laboratórios de informática, com $37,1 \%$ de equipamentos que não atenderem às necessidades, e 31,4\% referentes aos equipamentos em desuso/obsoletos.

Gráfico 3: Estado de uso dos equipamentos dos laboratórios de informática



Fonte: acervo pessoal

No que diz respeito aos equipamentos mais utilizados, ou seja, ao uso constante dos equipamentos da escola, foram PC/Notebook (68,6\%), seguidos pelo Datashow (60\%) e Impressora (51,4\%). Quanto aos menos utilizados, encontramos o DVD $(17,1 \%)$ e a TV Pendrive (25,7\%), respectivamente. Infere-se deste resultado, que o DVD e TV Pendrive, por exemplo, são dois dos instrumentos que tendem à obsolescência pela pouca utilização. Não consideramos, nesse estudo, a resposta dos professores quanto ao Tablet $(3,8 \%)-$ menor 
índice de utilização - por que são raras as escolas que as possuem como equipamento em suas instalações.

Gráfico 4: Equipamentos da escola de uso constante

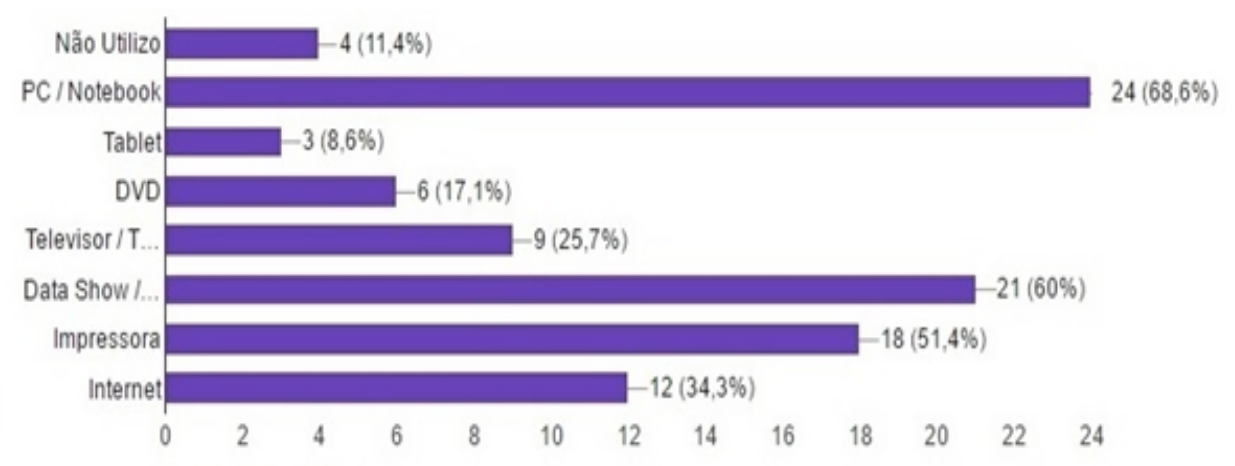

Fonte: acervo pessoal

Quanto a resposta sinalizada como Não Utilizo (11,4\%), aponta uma cultura da não utilização dos equipamentos e espaços tecnológicos, o que denota um distanciamento dos professores frente a educação que indaga, critica e inclui digitalmente, conforme preceitua a Lei Geral de Acesso à Informação do Brasil.

\section{Conclusão}

É indiscutível que a sala de aula seja o grande laboratório de ensino e aprendizagem, mas a extensão do ensino para outros espaços é uma característica nas inovações do ensino do mundo moderno, com prevalência do uso constante da tecnologia como mediadora, também, da aprendizagem.

Verificou-se com esta pesquisa, um expressivo número de professores que não fazem uso constante e efetivo do laboratório de informática como um espaço de aprendizagem e saber. Contrários aos pensamentos dos autores referendados neste artigo, que primam pelo uso destes espaços e seus equipamentos como um processo mediador de aceleração da aprendizagem, percebemos que a maioria dos entrevistados está alheia e desinteressada em utilizar os equipamentos tecnológicos disponíveis em suas escolas.

Decerto, que o cenário da pesquisa tem encontrado alguns vestígios por parte de alguns professores com interesse em usar os espaços e equipamentos, entretanto, esses vestígios ainda são insuficientes para contemplar a demanda ociosa de alunos dispostos a 
utilizarem os equipamentos e espaços extras, além da sala de aula. A esse respeito, Santos (2006) esclarece que ainda existem escolas que não se deram conta da importância desses espaços para o processo de aprendizagens e, infelizmente negam a presença das tecnologias no cotidiano escolar.

A pesquisa apontou um cenário escolar repleto de equipamentos velhos e novos em desuso, sendo desgastados pelo tempo em inatividade. A TV Pendrive já não está atendendo aos requisitos tecnológicos necessários da atualidade; o DVD está sendo substituído por outros equipamentos, que contemplem a conectividade com a internet, em amplo acesso aos conteúdos de áudio e vídeo, disponíveis nos canais da web.

Mesmo com tantas mudanças e inovações, constatou-se que um grande número de professores raramente vai aos laboratórios, raramente fazem planejamento de atividades para serem realizadas nesses espaços para uso integrativo da aprendizagem, imprimindo uma ideia de que seja pouco relevante a visita periódica ao laboratório. É o que apontou o diagnóstico desta pesquisa.

\section{Referências}

ALENCAR, A. F. D. Artigo científico: O pensamento de Paulo Freire sobre a Tecnologia: Traçando novas perspectivas, São Paulo, 2005.

BARDIN, L. Analise de Conteúdo. Lisboa: Edicões 70, 2009.

BORBA, M. C.; CHIARI, A.S.S.. Tecnologias Digitais e Educação Matemática. 1. ed. São Paulo: LF Editorial, 2013.

BORBA, M. C.; SCUCUGLIA, R. R. S. ; GADANIDIS, G. Fases das tecnologias digitais em Educação Matemática: sala de aula e internet em movimento . São Paulo: Autêntica, 2014.

EDMÉA SANTOS, L. A. Práticas pedagógicas e tecnologias digitais. Rio de Janeiro: EPapers, 2006.

FERRARI, A. T. Metodologia da ciência. Rio de Janeiro: Kennedy, 1974.

FIORENTINI, D.; LORENZATO, S. Investigacao em educação matemática - Percursos teóriocos e metodológicos. 3. ed. São Paulo: Autores Associados, 2006.

FREIRE, P. Educação e Mudança. Rio de Janeito: Paz e Terra, 1976.

FREIRE, P. A máquina está a serviço de quem?, p. 6, 1984. 
FREIRE, P. A máquina está a serviço de quem? Revista BITS, São Paulo, v. 1, n. 7, p. 6, Maio 1984.

GIL, A. C. Como Elaborar Projetos de Pesquisa. 4. ed. São Paulo: ATLAS, 2002.

GUSMÃO, T. C. R. S. Em Carta: Razão e Emoção na Sala de Aula. Vitória da Conquista: Ediçoes UESB, 2009.

JOSÉ. DynaTAC 8000x, el primer móvil de la historia. Abadia Digital, 2007 Setembro 2007. Disponivel em: $\quad<$ http://www.abadiadigital.com/dynatac-8000x-el-primer-movil-de-lahistoria/>. Acesso em: 26 Novembro 2016.

KENSKI, V. M. Aprendizagem mediada pela tecnologia. Diálogo Educacional, Curitiba, v. 4, n. 10, p. 47-56, Setembro 2003.

Cadernos de Pedagogia Universitária. Sao Paulo: USP, v. 7, 2008.

. Novos processos de interação e comunicação no ensino mediado pelas

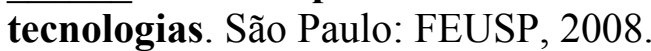

MARCONI, M. D. A.; LAKATOS, E. M. Fundamentos de Metodologia Científica. São Paulo: ATLAS, 2010.

MORAN, J. M. Os novos espaços de atuação do professor com as tecnologias. Revista Diálogo Educacional, Curitiba, v. 4, n. 12, p. 13-21, Maio/Ago. 2004.

MOZGA, M. O. El teléfono soviético de Kupriyanov. LIVEJORNAL, 30 Agosto 2013. Disponivel em: <http://brainexpo.livejournal.com/8873.html>. Acesso em: 17 Novembro 2016.

OPS. História do Celular nasceu em 1947. OPS. Disponivel em: $<$ http://www.ops.com.br/noticia/261/historia-do-celular-nasceu-em-1947>. Acesso em: 06 nov 2016.

PERRENOUD, P. Construir as competências desde a escola. Porto Alegre: Artes Médica, 1999.

PROLETÁRIA, C. El teléfono móvil, más comunista de lo que usted imagina. Cultura Proletária, 26 Janeiro 2014.2 Disponivel em: $<$ https://culturaproletaria.wordpress.com/2014/01/26/el-telefono-movil-mas-comunista-de-loque-usted-imagina/> . Acesso em: 2016 Novembro 2016.

ROSSII. El primer teléfono móvil del mundo. opccuu. Disponivel em: $<$ http://www.opoccuu.com/pervyj-mobilnik.htm>. Acesso em: 17 Novembro 2016.

SANTOS, L. M. A.; TAROUCO, L. M. R. A importância do estudo da Teoria da Carga Cognitiva em uma educação tecnológica. CINTED-UFRGS, v. 5, Julho 2007.

SILVA, M. D. F. D. O Computador na Formação Inicial do Professor de Matemática: um estudo a partir das perspetivas de alunos-professores. Unesp Rio Claro, Rio Claro, p. 33. Disponivel em: $<$ http://www.rc.unesp.br/gpimem/downloads/dissertacoes/silva_mdf_me _rcla.pdf $>$. Acesso em: 11 novembro 2016. 
SWELLER, J. Cognitive Load Theory: A Special Issue of educational Psicologist. [S.1.]: LEA, 2003.

UNESCO. Internet-Governance. UNESCO, 2016. Disponível em: $<$ http://www.unesco.org/new/pt/brasilia/communication-and-information/access-toknowledge/internet-governance/>. Acesso em: 06 Novembro 2016.

\section{Notas}

\footnotetext{
${ }^{\mathrm{i}}$ Mestrando do Programa de Pós-Graduação em Ensino (PPGEn) pela Universidade Estadual do Sudoeste da Bahia - UESB - Campus de Vitória da Conquista, na área de concentração em Ensino na Educação Básica, Membro do Grupo de Pesquisa GDCEM.

ii Professora Dr ${ }^{\mathrm{a}}$ adjunta do Departamento de Ciências Exatas e Tecnológica (DCET) da UESB, professora do PPGEn, coordenadora do Grupo de Pesquisa.

iii Pequeno aparelho de rádio emissor e receptor, que uma pessoa pode usar para se comunicar a uma distância relativamente curta; transceptor manual ou portátil.
}

\section{Sobre os autores}

José Eduardo Rocha Silva. Graduado em Administração pela Faculdade Juvêncio Terra; Mestrando do Programa de Pós-Graduação em Ensino (PPGEn) pela UESB Campus de Vitória da Conquista, na área de concentração em Ensino na Educação Básica; Bolsista CAPES; Pesquisador do Grupo de Estudos e Pesquisas em Didática das Ciências Experimentais e da Matemática (GDICEM), atuando na linha de pesquisa Matemática Emocional.

Maria Deusa Ferreira da Silva. Pós- Doutorado em Educação Matemática (UNESP-Rio Claro); Professora Titular da Universidade Estadual da Bahia - UESB Campus Vitória da Conquista; Coordenadora do Programa de Pesquisa em Educação Matemática Campus Vitória da Conquista (BA). 